\title{
STRATEGI KONSERVASI LAHAN PERTANIAN BERBASIS REINTERPRETASI RITUAL PERANG KETUPAT SEBAGAI DAYA TARIK WISATA DI DESA KAPAL KABUPATEN BADUNG
}

\author{
I. M. Sendra ${ }^{1}$ dan Y. Kristianto ${ }^{2}$
}

\begin{abstract}
ABSTRAK
Pengabdian institusi ini bertujuan untuk mengimplementasikan hasil penelitian sebelumnya. Target khusus pengabdian adalah (1) mengimplementaskan praktik kepariwisataan sebagai strategi melting pot dalam mempertahankan lahan pertanian di Desa Kapal, (2) mengimplementasikan praktik kepariwisataan dengan melatih dan mendampingi masyarakat Desa Kapal agar memiliki partisipasi dalam kegiatan pariwisata budaya yang berbasis budaya agraris, dan (3) pelatihan dan pendampingan dalam perencanaan, pengemasan, dan promosi paket wisata budaya agraris di Desa Kapal. Kegiatan dilaksanakan selama 6 bulan dengan teknis pelatihan dan pendampingan (1) pelatihan mengenal potensi daya tarik wisata budaya di Desa kapal, (2) pelatihan merencanakan dan membuat paket wisata budaya di Desa Kapal, (3) pelatihan pemanduan wisata budaya, (4) pendampingan pembuatan jejaring promosi dengan biro perjalanan wisata, dan (5) pelatihan pembuatan brosur dan calendar of event wisata budaya di Desa Kapal.
\end{abstract}

Kata kunci : perang ketupat, melting pot, lansekap pariwisata ekokultural, calendar of event

\begin{abstract}
The specific targets of devotion are (1) implementing tourism practices as a melting pot strategy in maintaining agricultural land in Kapal Village, (2) implementing tourism practices by training and assisting Kapal Village communities to have participation in cultural tourism activities based on agrarian culture, and (3) training and mentoring in the planning, packaging, and promotion of agrarian cultural tour packages in Kapal Village. This activity is carried out for 6 months with technical training and mentoring by (1) training how to identify the potential tourist attraction (2) training in planning and creating cultural tourism packages in Kapal Village, (3) cultural tourism guide training, (4) facilitation of making promotion network with travel agency, and (5) training on brochures and calendar of cultural tourism events in Kapal Village.
\end{abstract}

Keywords : ketupat war, melting pot, landscape of ecocultural tourism, calendar of event

\section{PENDAHULUAN}

Berdasarkan hasil analisis situasi desa kapal, maka pengabdian ini berupaya mengimplementasikan praktik kepariwisataan sebagai strategi yang bisa dilakukan untuk mencegah fenomena masifnya alih fungsi lahan di desa adat kapal. di samping itu, pengabdian ini bermanfaat bagi masyarakat desa kapal untuk mengenali potensi pariwisata berbasis budaya agraris yang dapat dikembangkan

\footnotetext{
1 Dosen Program Studi Industri Perjalanan Wisata, Fakultas Pariwisata, Universitas Udayana, Badung - Bali, sendramade65@gmail.com

2 Dosen Program Studi Industri Perjalanan Wisata, Fakultas Pariwisata, Universitas Udayana, Badung - Bali, inselbali@yahoo.com
} 
dan dikemas menjadi atraksi wisata. Selanjutnya, ritual perang ketupat dapat dijadikan kalender tahunan atraksi dan daya tarik wisata budaya, sehingga masyarakat lokal (winisatawan) memperoleh manfaat secara sosial (kembali bekerja sama secara tulus), budaya (memiliki kebanggaan mewarisi kearifan lokal agraris), spiritual (menghidupkan kembali medan energi positif) dan ekonomi (mendapatkan keuntungan material).

Berdasarkan analisis situasi di Desa Kapal, maka dapat diidentifikasikan permasalahan (1) perlunya identifikasi atraksi wisata yang berkaitan dengan budaya agraris di desa Kapal, (2) perlunya pendampingan untuk meningkatkan partisipasi masyarakat dalam praktik kepariwisataan agraris untuk menciptakan masyarakat yang sadar wisata; dan (3) perlunya pelatihan pengemasan paket wisata budaya agraris dan membuat jaringan dengan pihak industri, serta kegiatan pemanduan wisata.

Pelaksanaan pengabdian ini melibatkan khalayak sasaran yang mencakup 45 warga Desa Adat Kapal yang terdiri dari prajuru desa, generasi muda, dan kelompok sadar wisata. Target pengabdian ini secara strategis dapat mencapai: (1) identifikasi potensi ritual perang ketupat sebagai daya tarik wisata; (2) perencanaan aktifitas wisata berbasis eko-kultural; (3) pengemasan paket wisata budaya berbasis ritual perang ketupat, dan (4) pembuatan kalender tahunan rangkaian acara ritual perang ketupat

\section{METODE PELAKSANAAN}

Pengabdian institusi ini dilakukan dengan cara memberikan pendidikan dan pelatihan yang meliputi pemberian ceramah, diskusi, dan simulasi (praktek langsung) sebagai pemandu perjalanan wisata yang benar, serta membuat paket wisata yang baik dan dapat dituangkan dalam bentuk brosur yang menarik.

Tabel 1. Tahapan Kegiatan Pengabdian Institusi 2017 di Desa Kapal

\begin{tabular}{|c|c|c|c|c|}
\hline No & Nama Kegiatan & Deskripsi Kegiatan & Hasil Kegiatan & Pelaksana \\
\hline 1 & $\begin{array}{l}\text { Diskusi Lansekap Eko- } \\
\text { kultural Desa Kapal }\end{array}$ & 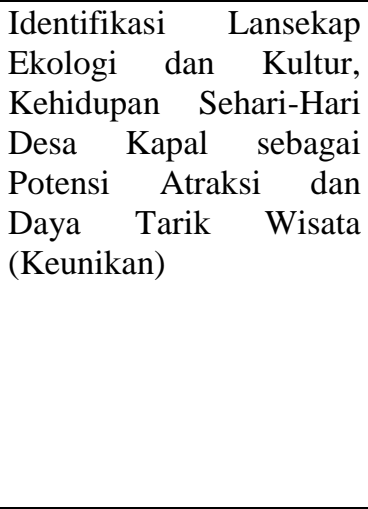 & $\begin{array}{l}\text { Desain Pariwisata Minat } \\
\text { Khusus } \\
\text { Kapal sebagai Desa Transisi } \\
\text { (Daily Life)> Pembuatan } \\
\text { Gerabah } \\
\text { Tradisional>Perang Ketupat } \\
\text { Konsep wisata Something to } \\
\text { learn } \\
\text { One Village---One Village }\end{array}$ & $\begin{array}{c}\text { Tim } \\
\text { Pengabdian } \\
\text { Unud, } \\
\text { Pokdarwis, } \\
\text { Pengelola } \\
\text { Kapal Village } \\
\text { Ecotourism }\end{array}$ \\
\hline 2 & $\begin{array}{lr}\text { Diskusi } & \text { dengan } \\
\text { Stakeholder } & \text { yang } \\
\text { terlibat } & \text { Praktik } \\
\text { Pariwisata } & \\
\end{array}$ & FGD & $\begin{array}{l}\text { Produk Wisata Minat } \\
\text { Khusus }\end{array}$ & $\begin{array}{l}\text { Tim, Prajuru } \\
\text { Desa, Karang } \\
\text { Taruna, } \\
\text { Swasta } \\
\end{array}$ \\
\hline 3 & $\begin{array}{lrr}\text { Diskusi } & \text { Praktik } \\
\text { Pariwisata yang } & \text { sudah } \\
\text { berjalan dan } & \text { yang } \\
\text { direncanakan beserta } & \text { bermasalahannya } \\
\end{array}$ & FGD & $\begin{array}{l}\text { Implementasi Produk } \\
\text { Wisata Minat Khusus }\end{array}$ & $\begin{array}{c}\text { Tim, Prajuru } \\
\text { Desa, Karang } \\
\text { Taruna, } \\
\text { Swasta }\end{array}$ \\
\hline 4 & $\begin{array}{l}\text { Pembuatan Visualisasi } \\
\text { Lansekap Eko-kultural } \\
\text { Desa Kapal }\end{array}$ & $\begin{array}{lr}\text { Menempatkan visualisasi } \\
\text { /informasi } & \text { keunikan } \\
\text { pembuatan } & \text { gerabah } \\
\text { tradisional } & \end{array}$ & Neon Box, pamphlet, baliho & Tim \\
\hline
\end{tabular}




\begin{tabular}{|c|l|l|l|c|}
\hline 5 & $\begin{array}{l}\text { Pembuatan Brosur } \\
\text { Wisata Eko-Kultural } \\
\text { Desa Kapal }\end{array}$ & $\begin{array}{l}\text { Membuat } \\
\text { ekokultural }\end{array}$ & Brosur paket wisata \\
\hline 6 & $\begin{array}{l}\text { Mapping Rute } \\
\text { Perjalanan Wisata Eko- } \\
\text { kultural }\end{array}$ & $\begin{array}{l}\text { Membuat rute perjalanan } \\
\text { wisata minat khusus }\end{array}$ & Map wisata minat khusus & Tim \\
\hline 7 & $\begin{array}{l}\text { Pembuatan Calender of } \\
\text { Event Desa Kapal } \\
\text { (Perang Ketupat) }\end{array}$ & $\begin{array}{l}\text { Merunut kronologis ritual perang } \\
\text { ketupat }\end{array}$ & $\begin{array}{l}\text { Calender of Eangkaian Perang Ketupat } \\
\text { Rant }\end{array}$ & Tim \\
\hline
\end{tabular}

\section{HASIL DAN LUARAN YANG DICAPAI}

Kegiatan pengabdian institusi di Desa Kapal menghasilkan (1) Lansekap Pariwisata Eko-Kultural di Desa Kapal, (2) Konsep Pengembangan Wisata Budaya berbasis Ritual Perang Ketupat, (3) Ancangan Kemasan Paket Wisata Ritual Perang Ketupat, dan (4) Ancangan Calender of Event Ritual Perang Ketupat. Adapun luaran yang dicapai (1) draft Brosur Wisata Ritual Perang Ketupat dan (2) itenerary paket wisata Desa Kapal. Berikut disajikan draft brosur wisata ritual perang ketupat dan paket wisata desa Kapal.

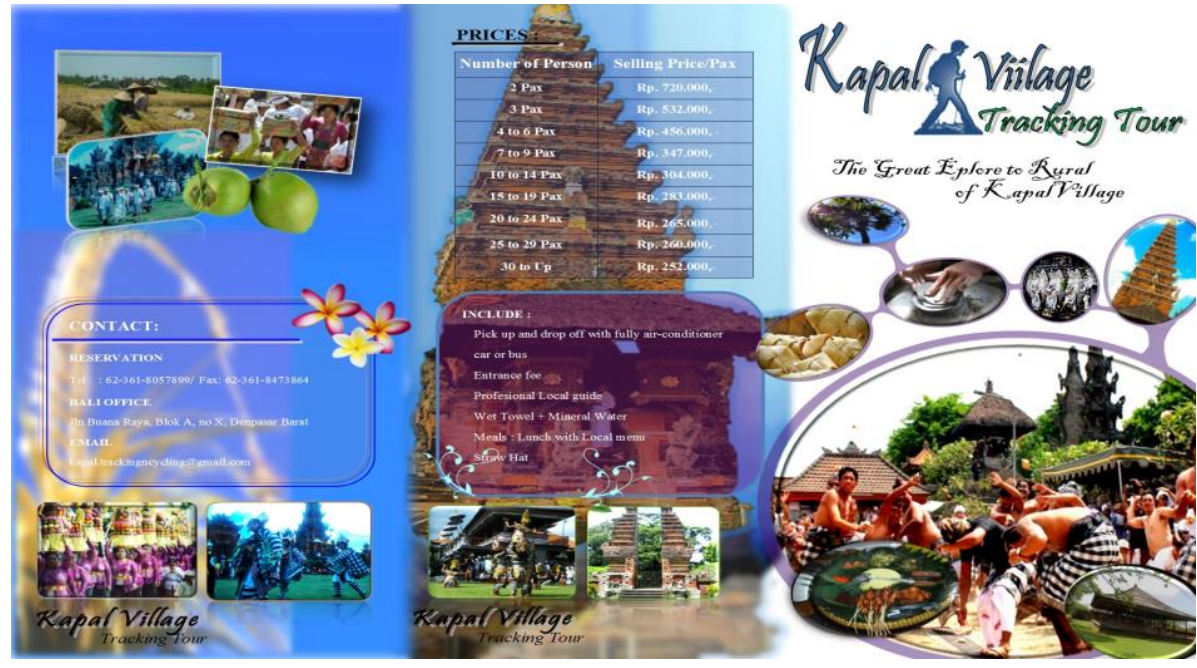

Gambar 1. Brosur dari Sisi Depan

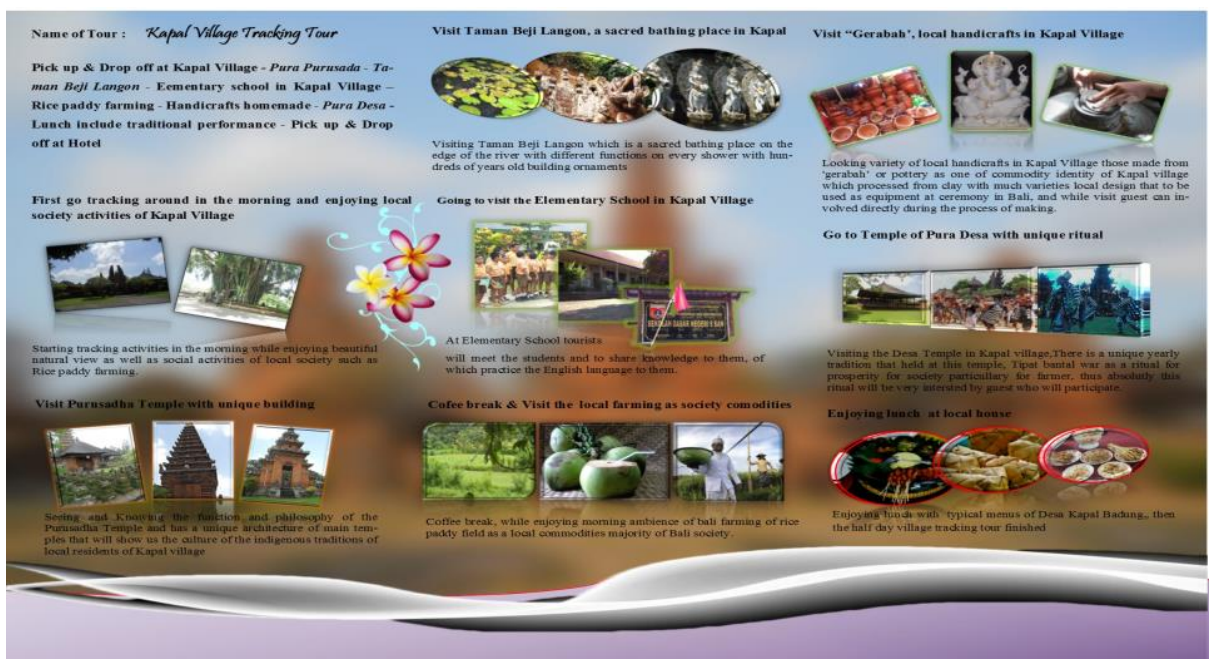

Gambar 2. Brosur dari Sisi Belakang 
Selanjutnya, disajikan deskripsi paket wisata desa Kapal berdasarkan perencanaan kunjungan dalam bentuk tabel berikut.

Tabel 2. Paket Wisata Desa Kapal

\begin{tabular}{|c|c|c|c|c|}
\hline \multirow{2}{*}{ DISCRIPTION } & \multicolumn{3}{|c|}{ DURATION } & \multirow{2}{*}{ TOTAL } \\
\hline & On Board & Tour Activity & Rest & \\
\hline Start Point - Pura Purusada Kapal & 5 , & - & - & 5 , \\
\hline * Pura Purusada Kapal (stop point 1) & - & $25^{\prime}$ & - & $25^{\prime}$ \\
\hline Pura Purusada - (stop point 2$)$ & $15{ }^{\prime}$ & - & - & $15^{\prime}$ \\
\hline * Taman Beji Langon & - & 30 ' & - & 30 ' \\
\hline Taman Beji - SD Kapal (stop point 3) & 5 , & - & - & 5 \\
\hline * Sekolah Dasar Desa Kapal & - & $35^{\prime}$ & 5 & $40^{\prime}$ \\
\hline stop point 3 - Pembuatan Kerajinan lokal & 15 ' & - & - & 15 , \\
\hline $\begin{array}{l}\text { Melihat proses pembuatan } \\
\text { kerajinan berbahan Gerabah } \\
\text { (handicraft) }\end{array}$ & - & 30 & $15^{\prime}$ & $45^{\prime}$ \\
\hline stop point 4 - Pura Desa & $10^{\prime}$ & - & - & $10^{\prime}$ \\
\hline $\begin{array}{l}\text { PPura Desa adat Kapal (stop point } \\
5 \text { ) }\end{array}$ & - & 30 & 5 & 35 , \\
\hline stop point 5 - Rumah lokal (lunch) & $15^{\prime}$ & - & - & $15^{\prime}$ \\
\hline * Lunch (finish point) & - & $60^{\prime}$ & $15^{\prime}$ & $65^{\prime}$ \\
\hline GRAND TOTAL & $\begin{array}{c}\text { 65' } \\
(1 \mathrm{Jam} 5)\end{array}$ & $\begin{array}{c}\text { 210' } \\
\text { (3 Jam 30') }\end{array}$ & $40^{\prime}$ & $\begin{array}{c}\text { 315' } \\
\text { ( } 5 \text { Jam 15') }\end{array}$ \\
\hline
\end{tabular}

\section{KESIMPULAN DAN SARAN}

Berdasarkan hasil pengabdian dan luaran yang dicapai hingga sejauh ini, maka dapat disimpulkan (1) Masyarakat Desa Kapal belum memahami potensi ritual perang ketupat sebagai daya tarik wisata budaya yang unik; (2) Desa Kapal memiliki lansekap pariwisata eko-kultural yang unik dan berbeda dengan desa wisata lainnya; (3) Desa Kapal memiliki topografi dan letak geografis yang strategis bagi pengembangan kepariwisataan; dan (4) Desa Kapal hanya menjadi jalur perlintasan menuju daya tarik wisata utama Jatiluwih, Bedugul, Alas Kedaton, Pura Taman Ayun, dan Pura Tanah Lot.

Berdasarkan kesimpulan sementara di atas, maka tim pengabdi dapat memberikan beberapa saran (1) Perlunya pemetaan potensi wisata budaya di Desa Kapal khususnya terkait perang ketupat;(2) Perlunya pembuatan brosur wisata eko-kultural tentang Desa Kapal;(3) Perlunya magnitude kegiatan wisata yang mampu menjaring wisatawan yang melintasi Desa Kapal; dan (4) Perlunya buku descriptor tentang daya tarik wisata eko-kultural di Desa Kapal khususnya yang terkait dengan rangkaian acara perang ketupat untuk mengenalkan potensi Desa Kapal di samping daya tarik wisata utama lainnya.

\section{UCAPAN TERIMAKASIH}

Tim Pengabdi mengucapkan terima kasih kepada LPPM Universitas Udayana yang telah memberikan dana Pengabdian Institusi 2017, sehingga tim dapat melaksanakan salah satu tugas Tri Dharma perguruan tinggi. 


\section{DAFTAR PUSTAKA}

LPPM UNUD. 2016. Panduan Penelitian dan Pengabdian kepada Masyarakat. Denpasar. LPPM UNUD. Sendra, Made., dkk. 2016. Ritual Perang Ketupat sebagai Strategi Konservasi Lahan Pertanian di Desa Kapal, Kecamatan Mengwi, Kabupaten Badung. Laporan Penelitian. Denpasar: LPPM Unud.

Sendra, Made, dkk. 2017. Eco-Cultural Tourism Landscape as A Concept of Tourism Practices in Bali $8^{\text {th }}$ International Science, Social Science, Engineering and Energy Conference, $15^{\text {th }}-17^{\text {th }}$ March,2017, The A-ONE Royal Cruise Hotel, Pattaya Beach, Thailand. 